\title{
BMJ Open Financial performance of English NHS trusts and variation in clinical outcomes: a longitudinal observational study
}

\author{
Myura Nagendran, ${ }^{1}$ Grace Kiew, ${ }^{2}$ Rosalind Raine, ${ }^{3}$ Rifat Atun, ${ }^{4}$ \\ Mahiben Maruthappu ${ }^{5}$
}

To cite: Nagendran M, Kiew G, Raine $\mathrm{R}$, et al. Financial performance of English NHS trusts and variation in clinical outcomes: a longitudinal observational study. BMJ Open 2019;9:e021854. doi:10.1136/ bmjopen-2018-021854

- Prepublication history and additional material for this paper are available online. To view these files, please visit the journal online (http://dx.doi. org/10.1136/bmjopen-2018021854).

Received 22 January 2018 Revised 24 October 2018 Accepted 25 October 2018

Check for updates

(c) Author(s) (or their employer(s)) 2019. Re-use permitted under CC BY-NC. No commercial re-use. See rights and permissions. Published by BMJ.

${ }^{1}$ NIHR Academic Clinical Fellow, Section of Anaesthetics, Pain Medicine and Intensive Care, Imperial College London,

London, UK

${ }^{2}$ Foundation Doctor, North West Anglia NHS Foundation Trust,

Peterborough, UK

${ }^{3}$ Professor, Department of Applied Health Care, University College London, London, UK

${ }^{4}$ Professor, Chan School of Public Health, Harvard University, Cambridge,

Massachusetts, USA

${ }^{5}$ CEO, Cera Care, London, UK

Correspondence to Dr. Myura Nagendran; myura.nagendran@imperial. ac.uk

\section{ABSTRACT}

Objectives To examine the association between financial performance as measured by operating margin (surplus/ deficit as a proportion of turnover) and clinical outcomes in English National Health Service (NHS) trusts.

Setting Longitudinal, observational study in 149 acute NHS trusts in England between the financial years 2011 and 2016.

Participants Our analysis focused on outcomes at individual NHS Trust-level (composed of one or more acute hospitals).

Primary and secondary outcomes Outcome measures included readmissions, inpatient satisfaction score and the following process measures: emergency department (Accident and Emergency (A\&E)) waiting time targets, cancer referral and treatment targets and delayed transfers of care (DTOCs).

Results There was a progressive increase in the proportion of trusts in financial deficit: $22 \%$ in $2011,27 \%$ in $2012,28 \%$ in $2013,51 \%$ in $2014,68 \%$ in 2015 and $91 \%$ in 2016 . In linear regression analyses, there was no significant association between operating margin and clinical outcomes (readmission rate or inpatient satisfaction score). There was, however, a significant association between operating margin and process measures (DTOCs, A\&E breaches and cancer waiting time targets). Between the best and worst financially performing Trusts, there was an approximately 2-fold increase in A\&E breaches and DTOCs overall although this variation decreased over the 6 years. Between the best and worst performing trusts on cancer targets, the magnitude of difference was smaller (1.16 and 1.15-fold), although the variation slowly rose during the 6 years.

Conclusions Operating margins in English NHS trusts progressively worsened during 2011-2016, and this change was associated with poorer performance on several process measures but not with hospital readmissions or inpatient satisfaction. Significant variation exists between the best and worst financially performing Trusts. Further research is needed to examine the causal nature of relationships between financial performance, process measures and outcomes.

\section{INTRODUCTION}

The combination of higher demand due to ageing, growing populations, with more chronic illness and disability, in addition

\section{Strengths and limitations of this study}

- To our knowledge, one of the first empirical exploratory analyses of the relationship between funding and outcomes in the English National Health Service.

- Operating margin may not be the ideal measure of an organisation's financial position.

- The proportion of activity at each Trust which is elective, acute or specialised was not taken into account nor was the percentage of activity subject to a national tariff.

- There may be additional unmeasured confounders that have impacted the results.

- This observational study is limited to demonstrating associations rather than causal links.

to rising treatment and technology costs, is driving increased health spending in high-income countries. ${ }^{1}$ The National Health Service (NHS) in England is introducing policies to address these demands, attempting to contain costs while improving health outcomes. The NHS Five Year Forward View, published in October 2014, set out a strategic vision for sustaining a high-quality, comprehensive health system in England. ${ }^{2}$ Specifically, it identified a £22 billion funding gap by $2020 / 2021$, based on the current funding trajectory of the NHS, to be met by ambitious efficiency savings of 2\%-3\% annually (given a long-term track-record of $1 \%$ each year).

The call for increased efficiency comes in an austere climate, in which individual NHS Trusts are progressively challenged to achieve financial control, ${ }^{3}{ }^{4}$ while responding to high demand, especially in winter months, reported widely in the British media. ${ }^{5}$ NHS Improvement, the body responsible for overseeing Trust performance, reported an overall third quarter deficit of $£ 886$ million for the 2016-2017 financial year, £300 million higher than the planned target. ${ }^{6}$ Higher demand for services, with rising emergency attendances and admissions, and delayed 
transfers of care (DTOCs) have been cited as key reasons for increasing deficit. ${ }^{7}$ While control of Trust financial deficits is important for sustainability of the NHS, there are concerns on the adverse impact of worsening financial performance on clinical outcomes and processes, ${ }^{8}$ but few studies which have explored this relationship.

We investigated the relationship between operating margin (surplus/deficit as a proportion of turnover) at English NHS Trusts during 2011-2016, with outcomes and process measures. We selected performance measures that are commonly used for benchmarking performance of NHS Trusts and that could plausibly be related to quality, namely, hospital readmissions, inpatient satisfaction scores, emergency department waiting time targets, cancer referral and treatment targets and DTOCs. ${ }^{9}$ Last, we investigated the variation in outcome and process measures between the financially best and worst performing Trusts, both overall and over time.

\section{METHODS}

\section{Data sources and extraction}

NHS Hospitals in England are categorised into financially and operationally distinct legal entities known as Trusts, which deliver services on behalf of the NHS. Trusts may be located at multiple sites and can be responsible for one or more hospitals. Well-performing Trusts are able to gain Foundation status, which allows a degree of financial and operational autonomy from the Department of Health. Data were sought for acute NHS Trusts in the 6-year period encompassing the financial years from April 2010 to March 2016.

We obtained financial data for Trusts from the gov. uk open data portal. ${ }^{10}$ Where information was lacking for specific Trusts, we sought the original data from the published accounts available on individual Trust websites or from NHS 'The Quarter' reports. ${ }^{11}$

Data on four financial metrics were extracted and examined: first, the retained surplus/deficit for the financial year; second, the turnover for the Trust (calculated as 'Revenue from patient care activities' and 'Other operating revenue'); third, trust spend on agency staff and fourth, spend on consultancy. The precise table IDs and subcodes for extraction are detailed in the online supplementary appendix 1. Only the first two metrics are measures of financial performance. The second two reflect Trust spending choices and we included these as exploratory variables given the public and media interest in rising agency and consultancy spend.

Bed availability for the quarter preceding the end of each financial year was obtained from publicly available NHS England data ${ }^{12}$ with occupancy rate calculated as the percentage of beds (as a proportion of total available) occupied on average during that quarter. Teaching status of the trusts was defined dichotomously on the basis of membership of The Association of UK University Hospitals. ${ }^{13}$ For each NHS Trust, the postcode of the Trust was extracted and used as a proxy for location to calculate the region of the country in which the trust hospitals were located.

This postcode data were matched to the 2015 Indices of Multiple Deprivation (IMD) score. ${ }^{14}$ The Office for National Statistics uses UK census data to generate the IMD score which encompasses census information from the following domains: income, employment, crime, living environment, health deprivation and disability, education and skills/training, barriers to housing and services.

Using publicly available NHS England datasets, we obtained data on hospital activity in the form of number of annual admissions per Trust and annual outpatient attendances. ${ }^{15}$ Data on last-minute elective operation cancellations (for non-clinical reasons) and the number of such patients not being treated within 28 days of such a cancellation were also extracted from publicly available NHS England datasets. ${ }^{15}$

\section{Outcome measures}

The outcomes we measured consisted of two clinical measures and three process measures that are commonly used for benchmarking NHS Trusts and have plausible mechanisms for a relation to quality. We openly acknowledge that there are several other outcomes and process measures which may also relate to quality and could have been chosen. Our selection was based on a combination of logistical constraints (ie, what data were publicly available) and an effort to include measures which are commonly used for benchmarking trusts and thereby also reported in the mainstream media. ${ }^{9}$

The clinical measures were (1) the proportion of discharges readmitted as an emergency within 7 days of discharge and (2) annual overall patient satisfaction for each trust using data from the National Adult Inpatient Survey compiled by the Care Quality Commission (CQC).${ }^{16}$ Data on readmissions were only available for the years 2014-2016. The three process measures were: (1) Accident and Emergency (A\&E) 4-hour waiting time breaches (2) DTOCs from an acute Trust and (3) cancer waiting time targets.

The first process measure, A\&E 4-hour waiting time breaches, was defined as the percentage of patient attendances in type 1 departments (major A\&E) who waited greater than 4 hours from arrival to admission, transfer or discharge.

The second process measure, a delayed transfer of care from an acute Trust, was said to occur when a patient was ready to depart from acute care but was still occupying a bed. These data were extracted as 'total number of bed days attributed to DTOCs' and standardised to number of beds available in the Trust. Delayed transfer of care data was only available for the latter 8 months of the 2011 financial year. To ensure comparability with other years, a 1.5× multiplier was applied for each trust in this financial year (see online supplementary appendix for further details). No other missing data in the study were imputed. 
For the third process measure, cancer waiting time targets, we assessed two specific targets (1) the proportion of patients who received a first consultant appointment within 2 weeks of urgent referral for suspected cancer by their general practitioner (GP) and (2) the proportion of patients who started a first treatment for cancer within 62 days of being urgently referred by their GP.

\section{Unit of analysis}

Our analysis focused on the outcomes at individual NHS Trust-level (composed of one or more acute hospitals).

\section{Statistical analysis}

Our financial metric of interest was the annual Trust operating margin. Similarly to prior literature, ${ }^{17-19}$ we defined operating margin as the retained surplus (or deficit) for the Trust in a financial year divided by the turnover (turnover being calculated as 'Revenue from patient care activities' and 'Other operating revenue'). This value was winsorised to set all outliers beyond the 2.5th and 97.5th percentiles to the values at these percentiles. We first calculated summary statistics of the operating surplus/ deficit and metrics of trust characteristics, breaking the sample into four groups of deciles by Trust margin.

As a second step, we compared the variation in process and outcome measures between the financially best and worst performing trusts as categorised by operating margin decile (highest versus lowest). Third, we performed multiple linear regression with our outcomes as the dependent variable and the following independent variables: operating margin, number of beds available and year. Each Trust in each year was treated as a separate observation with standard errors clustered by Trust to account for the non-independence of Trust-level data.

Fourth, we compared outcomes and process measures between 'struggling' and 'non-struggling' Trusts. For this purpose, a struggling Trust was defined as either: (1) in financial or quality special measures as of December 2016 or (2) a Foundation Trust subject to enforcement actions by Monitor as of September 2016. Fifth, we investigated the relationships between DTOCs, cancelled elective operations, agency spend, A\&E breaches and operating margin by assessing correlation between these variables over an early period (2011-2012) and a late period (2015-2016).

We performed sensitivity analyses to assess the impact of (1) adjustment for missing 2011 delayed transfer of care data and (2) inclusion of Trusts that had changed in composition during the study period.

All reported $p$ values are two sided with the statistical significance threshold set to a p value of less than 0.05 . Given the hypothesis generating nature of this study, no corrections were made for multiple comparisons. Approximately 1 in every 20 comparisons could be expected to achieve statistical significance by chance alone. All analyses were performed using STATA statistical software V.12.1 (College Station, Texas, USA). This study had no external funding source.

\section{Patient involvement}

Patients were not involved in any aspect of the study design, conduct or in the development of the research question or outcome measures. This study was a retrospective longitudinal observational study of publicly available Trust-level data and therefore there was no active patient recruitment for data collection or requirement for ethical approval.

\section{RESULTS}

Over the 6-year period of study, encompassing the financial years from April 2010 to March 2016, there were changes in the composition to 31 of 149 Trusts. These are detailed in the online supplementary appendix and took the form of creation of a new Trust, dissolution of an existing Trust, acquisitions of a hospital or entire Trust to another Trust and mergers between Trusts. 13 Trusts (9\%) transitioned to Foundation Status during the 6-year study period. Of the remaining 136 Trusts, 63 (42\%) were non Foundation Trusts and $73(49 \%)$ were Foundation Trusts.

There was a progressive increase in the proportion of Trusts in deficit over the 6-year study period: $22 \%$ in $2011,27 \%$ in $2012,28 \%$ in $2013,51 \%$ in $2014,68 \%$ in 2015 and $91 \%$ in 2016 . The distribution of average operating surplus/deficit over the study period is displayed in figure 1. Operating surplus/deficit varied widely across Trusts ranging from $-£ 250$ million to $£ 181$ million over the 6years. Median operating surplus/deficit over the study period was $-£ 3.8$ million (IQR $-£ 8.7$ million to -£0.7million, range $-£ 63.1$ million to $£ 32.6$ million). Median operating margin over the study period was $-1.1 \%$ (IQR $-2.7 \%$ to $-0.2 \%$, range $-42.5 \%$ to $4.6 \%$ ). Median operating margin was higher in teaching Trusts compared with non-Teaching Trusts $(-0.5 \%$ versus $-1.4 \%, \mathrm{p}=0.002)$ and lowest in the Midlands compared with other regions $(-2.3 \%$ in the Midlands, $-1.2 \%$ in London, $-0.8 \%$ in the South, $-1.0 \%$ in the North; $\mathrm{p}=0.028$ ).

During the 6-year study period, there was a nationwide decline in overnight general and acute beds from 110568 to 103422 (6.5\% reduction) with a concomitant increase in day only beds from 11572 to 12207 (5.5\% increase).

Trust metrics are shown in table 1 stratified by decile of operating margin. Between the best and worst financially performing Trusts, there was an approximately 1.75-fold and 2-fold increase in agency and consultancy spend, respectively, as a proportion of turnover. The best financially performing Trusts also had a 1.5-fold higher annual number of outpatient attendances. In contrast, the annual number of admissions, bed occupancy rates, local deprivation scores and proportion of Foundation Trusts were broadly similar between the best and worst performing Trusts. The proportion of Trusts with teaching status increased throughout deciles of operating margin. Trends in the variation of operating margin over time with clinical outcomes and process measures are displayed in figures 2 and 3, respectively. 


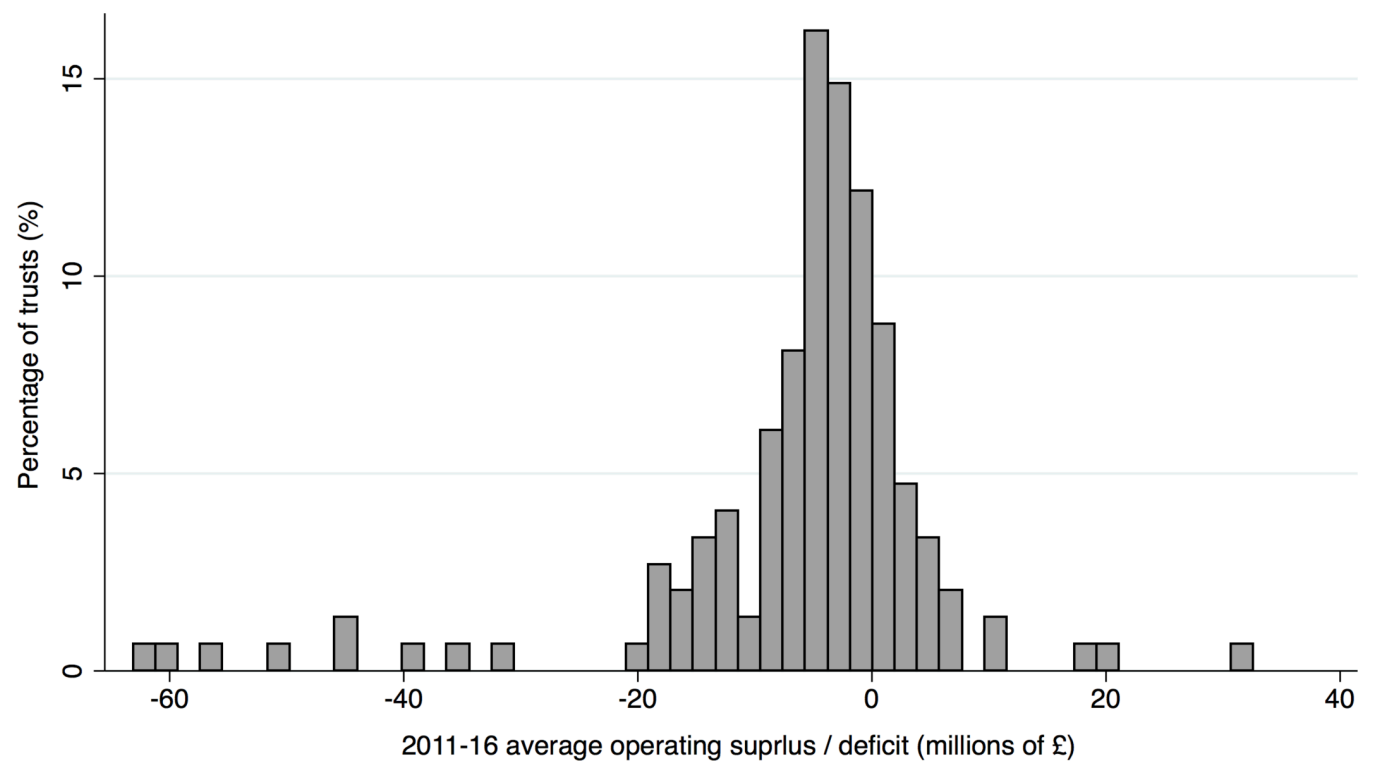

Figure 1 Distribution of average operating surplus/deficit over the 2011-2016 period.

Clinical outcomes and process measures, stratified by decile of operating margin, are shown in table 2. Between the best and worst financially performing Trusts, there was an approximately 2-fold increase in A\&E breach rates and DTOCs. In contrast, despite significant differences between the best and worst performing trusts on cancer targets, the magnitude of difference was smaller (both approximately 1.15 -fold).

Trends in the variation between the best and worst financially performing Trusts over time for both clinical outcomes and process measures are shown in table 3. There was no appreciable variation in readmission rate

Table 1 Trust metrics by decile of Trust operating margin

\begin{tabular}{|c|c|c|c|c|}
\hline & \multicolumn{4}{|l|}{ Operating margin } \\
\hline & Bottom 10\% & $11 \%-50 \%$ & $51 \%-89 \%$ & Top $10 \%$ \\
\hline $\begin{array}{l}\text { Operating surplus/deficit ( } £ \text { millions, } \\
\text { median (range)) }\end{array}$ & $-30.9(-61.1$ to -12.4$)$ & $-6.3(-63.1$ to -1.2$)$ & $-1.5(-13.8$ to 6.8$)$ & 5.4 (1.3 to 32.6$)$ \\
\hline $\begin{array}{l}\text { Agency spend as proportion of } \\
\text { turnover (\%) }\end{array}$ & $6.9(2.0)$ & $4.8(2.4)$ & $3.8(2.0)$ & $3.9(1.2)$ \\
\hline $\begin{array}{l}\text { Consultancy spend as proportion of } \\
\text { turnover }(\%)\end{array}$ & $0.96(0.54)$ & $0.44(0.35)$ & $0.45(0.74)$ & $0.46(0.29)$ \\
\hline Annual admissions, mean (SD) & 26978 (9698) & 29006 (13 326) & $36411(21300)$ & 30445 (12 455) \\
\hline $\begin{array}{l}\text { Annual outpatient attendances, mean } \\
\text { (SD) }\end{array}$ & 271508 (109 938) & $295223(142784)$ & 374266 (210 861) & 407595 (209 956) \\
\hline Bed availability, mean (SD) & $716(267)$ & $718(321)$ & $822(387)$ & $740(226)$ \\
\hline Bed occupancy (\%) & 90.1 & 88.3 & 87.2 & 88.1 \\
\hline Deprivation score, mean (SD) & $23.4(11.8)$ & $19.2(13.2)$ & $23.3(14.6)$ & $23.5(11.9)$ \\
\hline Teaching trust (\%) & 6.7 & 17.0 & 33.3 & 35.7 \\
\hline \multicolumn{5}{|l|}{ Foundation status (\%) } \\
\hline Non-foundation trust & 40.0 & 49.2 & 35.0 & 42.9 \\
\hline Foundation trust & 53.3 & 47.5 & 50.0 & 50.0 \\
\hline Transitioned to Foundation & 6.7 & 3.4 & 15.0 & 7.1 \\
\hline \multicolumn{5}{|l|}{ Region (\%) } \\
\hline London & 20 & 17 & 17 & 21 \\
\hline South & 20 & 17 & 38 & 7 \\
\hline Midlands & 40 & 36 & 15 & 29 \\
\hline North & 20 & 31 & 30 & 43 \\
\hline
\end{tabular}




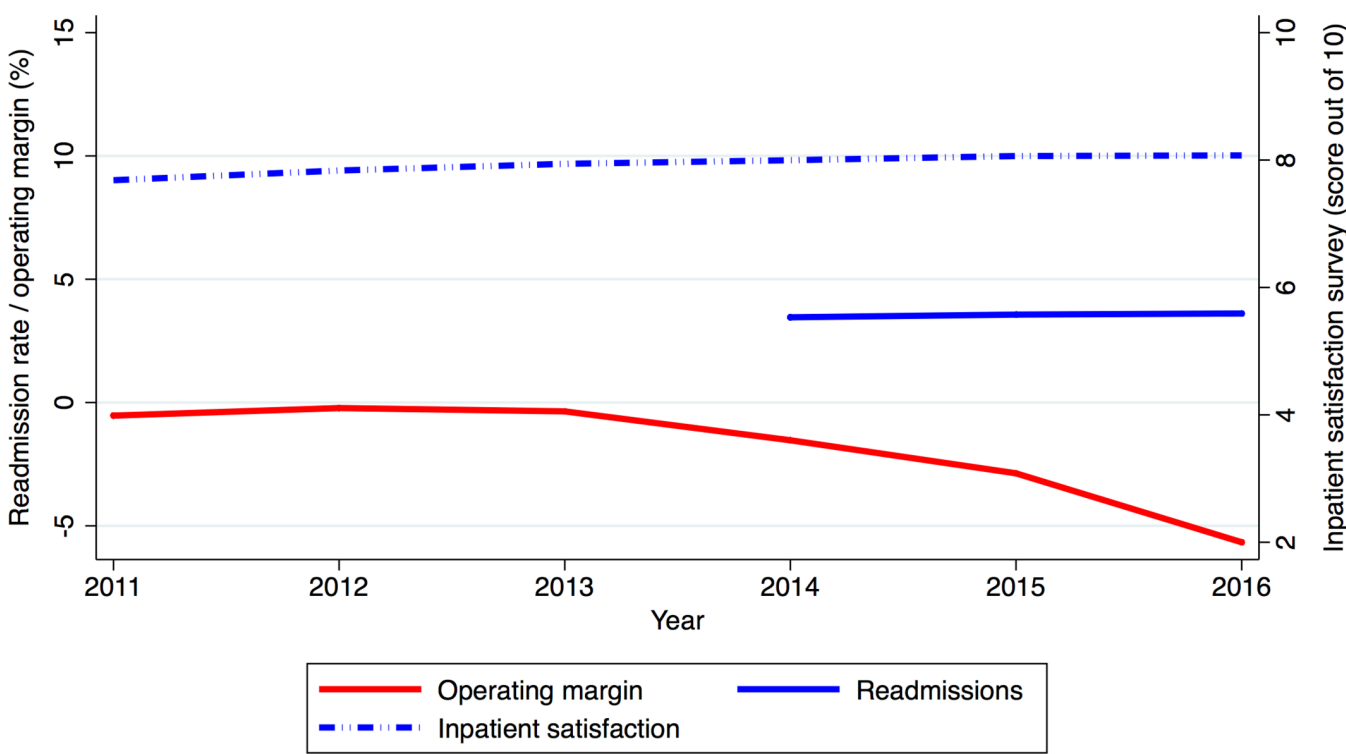

or inpatient satisfaction score with the latter increasing over time at a slightly faster rate in the worst financially performing Trusts.

Performance on process measures in both the best and worst financially performing Trusts deteriorated over time (table 3). However, variation between the best and worst groups narrowed for A\&E breaches, returned to baseline for DTOCs after an initial rise and rose slowly for both cancer target breaches. The variation in agency spend as a proportion of turnover between the best and worst financially performing trusts increased substantially between 2011 (best $2.7 \%$ and worst $3.9 \%$, difference $1.2 \%$ ) and 2016 (best $4.5 \%$ and worst $9.1 \%$, difference $4.6 \%$ ) (see table A in online supplementary appendix).

In our linear regression analyses, there was no significant association between operating margin and clinical outcomes (readmission rate or inpatient satisfaction score; table 4). There was, however, a significant association between operating margin and process measures (DTOCs, A\&E breaches and cancer waiting time targets; table 4). Trusts defined as struggling (ie, in special measures or subject to enforcement action) were associated with worse performance on all process measures but not with readmission rate or inpatient satisfaction scores (table 5). Foundation Trusts were associated with better performance on clinical outcomes and all process measures except DTOCs (see table B in online supplementary appendix 1). Broadly speaking, the associations between operating margins and outcomes/process measures were not as strong for Foundation Trusts as non-Foundation Trusts (see tables C1 and C2 in online supplementary appendix 1).

The associations between DTOCs, elective surgery cancellations, agency spend, A\&E breaches and operating
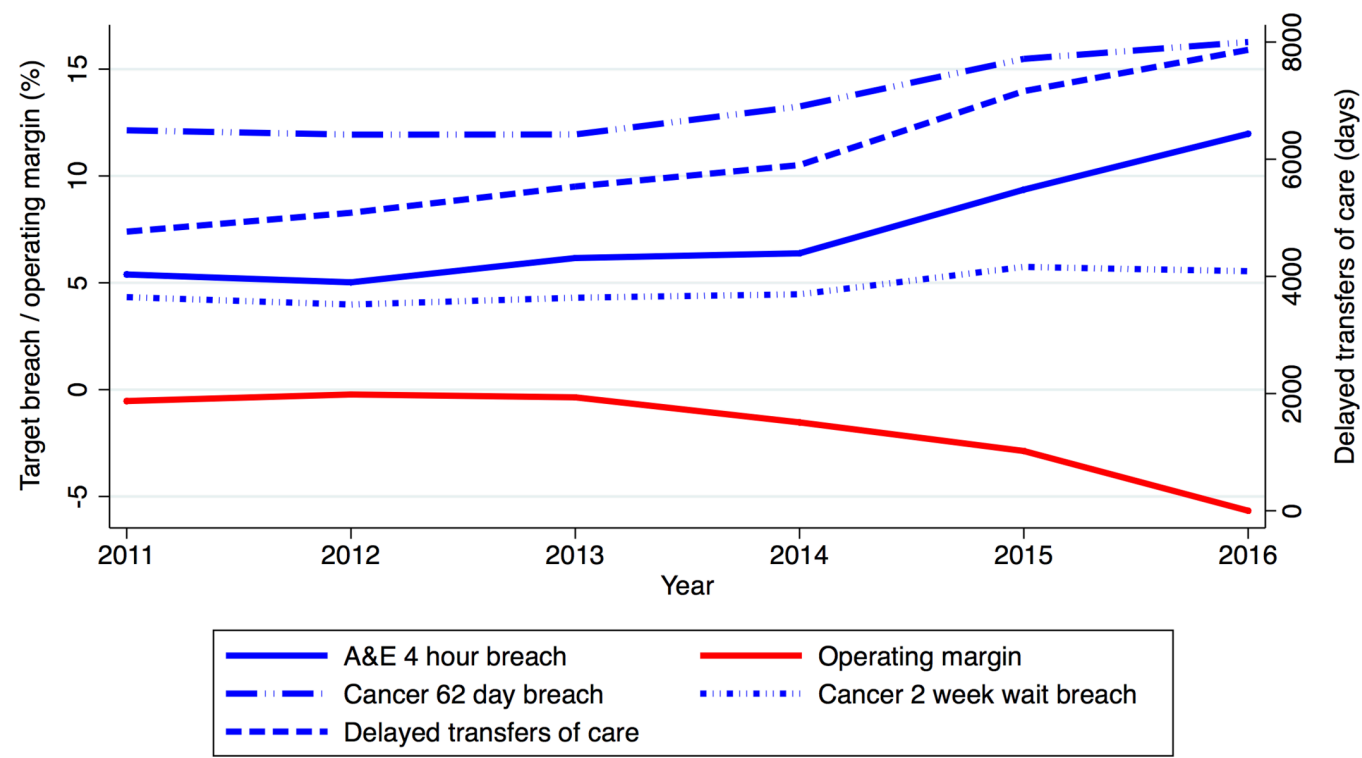

Figure 3 Trends in operating margin and process measures over time. A\&E, Accident and Emergency. 
Table 2 Outcomes/process measures by decile of Trust operating margin

\begin{tabular}{|c|c|c|c|c|c|}
\hline & \multicolumn{4}{|l|}{ Operating margin } & \multirow[b]{2}{*}{ P value } \\
\hline & Bottom $10 \%$ & $11 \%-50 \%$ & $51 \%-89 \%$ & Top $10 \%$ & \\
\hline Readmission rate (\%) & 3.6 (3.4 to 3.9$)$ & 3.6 (3.1 to 3.9$)$ & 3.7 (3.2 to 4.0$)$ & 3.3 (3.0 to 3.8$)$ & 0.137 \\
\hline 4 hour A\&E target breach rate (\%) & $10.2(6.7$ to 15.1$)$ & 6.7 (4.9 to 10.7$)$ & 5.3 (4.2 to 7.3$)$ & 5.3 (3.9 to 6.7$)$ & $<0.001$ \\
\hline $\begin{array}{l}\text { Cancer } 2 \text { week wait target } \\
\text { adherence }(\%)\end{array}$ & 94.9 (93.2 to 96.2 ) & 95.5 (94.2 to 96.7$)$ & 95.4 (94.4 to 96.7 ) & 95.6 (95.0 to 96.5$)$ & 0.009 \\
\hline $\begin{array}{l}\text { Cancer } 62 \text { days to first treatment } \\
\text { target adherence }(\%)\end{array}$ & 86.2 (81.9 to 88.2$)$ & 86.6 (83.6 to 89.1$)$ & 87.6 (85.6 to 89.6) & 88.0 (86.3 to 89.9) & $<0.001$ \\
\hline
\end{tabular}

A\&E, Accident and Emergency.

margins are displayed in a correlation matrix for the early years (2011 and 2012; figure 4) and the later years (2015 and 2016; figure 5) of the 6-year study period (same scale applied to both figures 4 and 5). There was weak positive correlation between all factors except operating margin for which there was weak negative correlation with the other measures. These associations were maintained in the later years though with a greater spread among trusts.

Sensitivity analyses are reported in the online supplementary appendix. There was no change to the results with and without adjustment for missing 2011 delayed transfer of care data (Table D in online supplementary appendix). There was no change to the results when excluding Trusts that had changed in composition over the study period (Table $\mathrm{E}$ in online supplementary appendix).

\section{DISCUSSION}

\section{Principal findings}

Our study has a number of important findings. First, in the period 2011-2016, there was a substantial increase in the proportion of NHS Trusts with negative operating margins. Second, the overall variation between the best and worst financially performing Trusts was larger for A\&E breach rates and DTOCs than for cancer targets. Third, the variation over time between the best and worst financially performing trusts was static for clinical outcomes and mixed for process measures (decreased over the 6years for A\&E breaches, was static for DTOCs while increasing slightly for cancer targets). Fourth, there was a significant association between worsened operating margin and deteriorating process measures (4hour A\&E targets, cancer waiting time targets and DTOCs), but not between operating margin and either readmission rates or inpatient satisfaction scores.

\section{Comparison with other studies}

The extant literature on the association between financial performance and outcomes comes primarily from the USA and is mixed in pronouncement. Volpp and colleagues assessed the impact of a budget act reducing Medicare reimbursements on processes of care for acute myocardial infarction (MI) ${ }^{20}$ They found that while the budget act added moderate financial strain to organisations, there was no appreciable worsening of care with respect to MI processes of care or mortality in 236506 patients from 208 hospitals. An analysis by Bazzoli and colleagues in 2008 concluded that while there may be an association between some measures of financial performance and adverse events, it was much weaker than previously reported by Encinosa and Bernard who found a concerning association between frequency of patient safety alerts and operating margin. ${ }^{17} 18$ Further, a study by Ly and colleagues in over 3000 US hospitals found that low hospital margins were associated with worse processes of care and higher readmissions, although not with higher mortality. ${ }^{21}$

Placing our findings in the context of earlier studies requires extreme caution given the differences between the US and UK health systems. Specifically, Ly et al excluded public hospitals (which comprise the vast majority of English hospitals) from their analysis. However, these prior studies do highlight the difficulty in disentangling the relationship between financial performance and outcomes. Meanwhile, a large European cohort study revealed that attempts to save money by cutting nurse to patient ratios may adversely affect patient outcomes. ${ }^{22}$ An increase in a nurses' workload by one patient increased the likelihood of a 30-day inpatient death by 7\% (OR $1.07,95 \%$ CI 1.03 to 1.11$){ }^{22}$

\section{Study limitations}

Our findings must be borne in light of several study limitations. First, while we had access to a considerable volume of data, the granularity of data was limited. For example, our unit of analysis was at the Trust level, giving a sample size of approximately 149 compared with equivalent US studies that have analysed over 3000 hospitals. ${ }^{21}$ Lack of 
Table 3 Variation in outcomes and process measures over time by Trust financial performance

\begin{tabular}{|c|c|c|c|c|c|c|}
\hline & 2011 & 2012 & 2013 & 2014 & 2015 & 2016 \\
\hline \multicolumn{7}{|l|}{ Readmissions (\%) } \\
\hline Worst $10 \%$ & - & - & - & 3.6 & 3.7 & 3.8 \\
\hline Middle $80 \%$ & - & - & - & 3.4 & 3.6 & 3.6 \\
\hline Best $10 \%$ & - & - & - & 3.4 & 3.5 & 3.6 \\
\hline Ratio of worst to best & - & - & - & 1.1 & 1.0 & 1.1 \\
\hline Difference (best and worst) & - & - & - & 0.2 & 0.1 & 0.2 \\
\hline \multicolumn{7}{|c|}{ Inpatient satisfaction survey (score out of 10) } \\
\hline Worst $10 \%$ & 7.5 & 7.7 & 7.9 & 7.9 & 8.0 & 8.0 \\
\hline Middle $80 \%$ & 7.7 & 7.8 & 7.9 & 8.0 & 8.1 & 8.1 \\
\hline Best $10 \%$ & 7.8 & 7.8 & 7.9 & 8.0 & 8.1 & 8.1 \\
\hline Ratio of worst to best & 1.0 & 1.0 & 1.0 & 1.0 & 1.0 & 1.0 \\
\hline Difference (best and worst) & 0.3 & 0.1 & 0.0 & 0.1 & 0.1 & 0.1 \\
\hline \multicolumn{7}{|c|}{ Accident and Emergency breach rate (\%) } \\
\hline Worst $10 \%$ & 8.2 & 6.4 & 7.8 & 7.8 & 11.9 & 13.6 \\
\hline Middle $80 \%$ & 5.2 & 4.9 & 6.0 & 6.3 & 9.3 & 12.0 \\
\hline Best $10 \%$ & 4.2 & 4.5 & 5.5 & 5.9 & 7.5 & 10.4 \\
\hline Ratio of worst to best & 2.0 & 1.4 & 1.4 & 1.3 & 1.6 & 1.3 \\
\hline Difference (best and worst) & 4.0 & 1.9 & 2.3 & 1.9 & 4.4 & 3.2 \\
\hline \multicolumn{7}{|l|}{ Delayed transfers of care days } \\
\hline Worst $10 \%$ & 5077 & 6657 & 7248 & 6972 & 7813 & 8284 \\
\hline Middle $80 \%$ & 4851 & 5082 & 5558 & 6046 & 7311 & 8044 \\
\hline Best $10 \%$ & 3850 & 3722 & 3884 & 3932 & 5712 & 6477 \\
\hline Ratio of worst to best & 1.3 & 1.8 & 1.9 & 1.8 & 1.4 & 1.3 \\
\hline Difference (best and worst) & 1227 & 2935 & 3364 & 3040 & 2101 & 1807 \\
\hline \multicolumn{7}{|c|}{ Cancer 2-week wait target breach rate (\%) } \\
\hline Worst $10 \%$ & 4.2 & 4.2 & 4.6 & 4.8 & 6.2 & 5.9 \\
\hline Middle $80 \%$ & 4.3 & 3.9 & 4.3 & 4.4 & 5.7 & 5.5 \\
\hline Best $10 \%$ & 4.6 & 4.1 & 4.0 & 4.6 & 5.9 & 5.2 \\
\hline Ratio of worst to best & 0.9 & 1.0 & 1.2 & 1.0 & 1.1 & 1.1 \\
\hline Difference (best and worst) & -0.4 & 0.1 & 0.6 & 0.2 & 0.3 & 0.7 \\
\hline \multicolumn{7}{|c|}{ Cancer 62 days to first treatment breach rate (\%) } \\
\hline Worst $10 \%$ & 11.9 & 11.7 & 12.2 & 13.7 & 16.6 & 18.3 \\
\hline Middle $80 \%$ & 12.1 & 12.0 & 12.2 & 13.4 & 15.6 & 16.2 \\
\hline Best $10 \%$ & 11.9 & 11.7 & 10.0 & 11.7 & 13.5 & 15.2 \\
\hline Ratio of worst to best & 1.0 & 1.0 & 1.2 & 1.2 & 1.2 & 1.2 \\
\hline Difference (best and worst) & 0.0 & 0.0 & 2.2 & 2.0 & 3.1 & 3.1 \\
\hline
\end{tabular}

'high-frequency' data also prevented us performing interrupted time-series and time-lag analyses.

Second, it may be that operating margin is not the ideal measure of an organisation's financial position. A Trust's deficit may be exaggerated if it realises that a deficit is unavoidable and careful accounting allows for a larger than necessary deficit in 1 year to ensure a small surplus in the following year (as opposed to 2years of deficit): potential gamification. ${ }^{23}$ Organisations including NHS Improvement and the Department of Health typically use breakeven performance figures instead of operating surplus/deficits. We chose not to use such figures as the data were not easily available at Trust level for much of the period under investigation.

Third, we used only a small selection of existing clinical outcomes and process. This decision was driven by two factors. Logistically, there is limited public access to many clinical outcomes. While there is access to many process measures, we opted for a small selection that is commonly used for benchmarking trusts (ie, often quoted in media 
Table 4 Association of operating margin on outcomes and process measures

\begin{tabular}{lllccc}
\hline Outcome & $\mathbf{n}$ & Trust clusters & Coefficient & $\mathbf{9 5 \%} \mathbf{C l}$ & $\mathbf{P}$ value \\
\hline Readmission rate (\%) & 387 & 135 & -0.012 & -0.029 to 0.005 & 0.164 \\
\hline Inpatient satisfaction score (out of 10) & 825 & 148 & 0.80 & -0.06 to 1.67 & 0.067 \\
A\&E 4-hour breach rate (\%) & 835 & 148 & -0.24 & -0.33 to -0.15 & $<0.001$ \\
Delayed transfers of care days per hospital bed & 837 & 148 & -25.1 & -39.1 to -11.0 & 0.001 \\
2-week wait cancer target adherence (\%) & 833 & 148 & 0.05 & 0.00 to 0.09 & 0.031 \\
62-day cancer treatment target adherence (\%) & 833 & 148 & 0.12 & 0.03 to 0.21 & 0.009
\end{tabular}

A\&E, Accident and Emergency.

reports and receive major public scrutiny) so as to avoid the issues of multiple comparisons. It is entirely possible that other process measures may well display differing relationships with respect to operating margins.

Fourth, we did not take into account the proportion of activity at each Trust which is elective, acute or specialised nor did we assess the percentage of activity subject to a national tariff. Work from the Health Foundation in 2016 suggests a link between financial performance and the proportion of Trust income arising from activities subject to the national tariff. ${ }^{24}$ Reimbursement prices for specialist activity tend to be higher than average treatment costs. Furthermore, best practice tariffs tend to reward more efficient treatment delivery such as an increased proportion of day cases. Although there is likely to be correlation between teaching hospital status (which we did assess) and the share of activity subject to a specialised services tariff, this is nonetheless a crude proxy.

Fifth, there may be additional unmeasured confounders that have impacted on our results. For example, surrounding Primary Care systems may impact on the efficiency with which the acute Trusts function. Or alternatively, competition from independent sector treatment centres may lead to a loss of revenue and market share for some Trusts, who may then need to invest more of their operating funds in attracting patients, especially given an increasing emphasis on patient choice and the freedom for patients to select hospitals by publicly reported outcomes. We adjusted for hospital size in the form of number of beds as well as using operating margin as a more standardised measure of financial performance than gross surplus or deficit (as turnover showed wide variation between trusts). Trusts that treat greater volumes of patients may benefit from economies of scale. However, as with any observational research, we cannot fully discount the impact of confounding on our results. For example, financial underperformance may be a signal of general underperformance in a Trust where clinical and other functions that might be suboptimal affect outcomes. Sixth, we are limited to demonstrating associations rather than causal links.

\section{CONCLUSION AND POLICY IMPLICATIONS}

Notwithstanding limitations, our findings have important ramifications for clinical leads, managers and policy makers. The relationship between financial performance and clinical outcomes is far more complex and associated with myriad other factors which will vary among Trusts. This is highlighted in a 2017 briefing from the Nuffield Trust which discusses the current financial health of Trusts and attempts to predict what is likely to occur in the coming years. ${ }^{23}$ Trusts with financial deficits may be spending more than they can afford (eg, on extra nursing staff) and one could therefore argue that higher quality should be expected for this extra financial outlay. Conversely, the existence of such deficit might instead indicate reduced efficiency and challenged management. Alternatively, financial penalties due to poor clinical performance or financial management could exacerbate deficits. For example, marginal rate payment reductions for emergency admissions, penalties for readmissions and

Table 5 Outcomes and process measures in trusts struggling (ie, in special measures or subject to enforcement action) versus those that are not

\begin{tabular}{lccc}
\hline & Struggling trust & Non-struggling trust & P value \\
\hline Readmission rate (\%) & $3.6(3.1$ to 3.9$)$ & $3.7(3.1$ to 3.9$)$ & 0.285 \\
Inpatient satisfaction score (out of 10) & $7.9(7.8$ to 8.1) & $7.9(7.8$ to 8.1$)$ & 0.378 \\
A\&E 4- hour target breach rate (\%) & $6.8(5.2$ to 10.2) & $5.5(4.2$ to 8.3$)$ & $<0.001$ \\
Delayed transfer of care days per hospital bed & $8.2(4.5$ to 11.9) & $6.4(4.0$ to 10.4$)$ & 0.005 \\
Cancer 2-week wait target adherence (\%) & $95.1(94.0$ to 96.4) & $95.5(94.4$ to 96.8) & 0.002 \\
Cancer 62 days to first treatment target adherence (\%) & $86.6(83.7$ to 88.9) & $87.4(84.8$ to 89.6$)$ & 0.002 \\
\hline
\end{tabular}

A\&E, Accident and Emergency. 




Figure 4 2011-2012 correlation between delayed transfers of care, elective operation cancellations, agency spend, A\&E breaches and operating margin. Elective surgery cancellations are last-minute elective operation cancellations (for non-clinical reasons) standardised in this figure to number of available beds at the Trust (as a proxy for hospital capacity). Agency spend is displayed as a proportion of turnover. Operating margin is as defined in study methods. A\&E, Accident and Emergency; DTOC, delayed transfer of care.

withholding payment for cases resulting in never events. Attempts to redress this balance may inadvertently lead to reflex spending cuts and poorer quality care. The role of clinical leads, management and leadership within a Trust is likely to be a key contributor to how financial deficits impact quality of care. For example, cutting down on management personnel to save costs may result



Figure 5 2015-2016 correlation between delayed transfers of care, elective operation cancellations, agency spend, A\&E breaches and operating margin. Elective surgery cancellations are last-minute elective operation cancellations (for non-clinical reasons) standardised in this figure to number of available beds at the Trust (as a proxy for hospital capacity). Agency spend is displayed as a proportion of turnover. Operating margin is as defined in study methods. A\&E, Accident and Emergency; DTOC, delayed transfer of care. in worse productivity if clinicians have to allocate more time to administrative activities and away from revenue producing clinical activities. In this regard, it is interesting that the associations between operating margins and outcomes/process measures were not as strong for Foundation versus non-Foundation Trusts. It may be that an earlier move to new reimbursement and funding models exposed Foundation Trusts to financial stress that inoculated them to some extent against later financial pressures.

There are a number of specific points to consider also. First, there is substantial variation between Trusts, which in some cases is worsening. Between the best and worst financially performing Trusts, there are up-to 2-fold differences in agency spend, DTOCs, A\&E breaches and cancer waiting times. This is notable and needs to be explicitly tackled with greater efficacy. While national regulators such as the CQC and NHS Improvement do seek to support challenged Trusts, the effectiveness of this has not necessarily translated into improved performance metrics. An argument could also be made that although the magnitude of difference in cancer targets was smaller than for A\&E breaches, there may be grater concern from even small increases in cancer waiting times compared with A\&E breaches which include less severe illnesses.

Second, the lack of significant association between operating margin and either readmissions or inpatient satisfaction may suggest that clinical outcomes are more resilient to financial pressures than process measures or that the driver for such clinical metrics is not predominantly financial-based. Third, the recent narrowing of variation between the best and worst performing Trusts on the measures of A\&E targets and DTOCs, may be a cause for concern, suggesting that now even the best financially performing Trusts are struggling to manage demand. This indicates that a more system-wide approach to demand-management and improving Trust performance may be required to address the identified deteriorations, given the entire Trust cohort is now showing signs of deterioration. Stated plainly, it seems that even if best practice is adopted from the most well managed Trusts, demands on secondary and tertiary care may not be adequately addressed.

Finally, studies assessing the microlevel spending decisions by Trusts when confronted by financial pressures may lend more insight into the causal pathway and suggest appropriate targets for intervention (see figure A in in online supplementary appendix).

\section{SUMMARY}

Notwithstanding limitations, our results demonstrate that operating margins at English NHS Trusts have progressively worsened over 2011-2016, and that this change correlates with poorer Trust performance on a range of widely benchmarked process measures, but not significantly with readmissions or inpatient satisfaction. 
The variation between the best and worst financially performing Trusts was larger for A\&E breach rates and DTOCs than for cancer targets but showed differing patterns of variation over time. The causal nature of relationships between financial performance, process measures and outcomes remains difficult to disentangle.

Acknowledgements BMJ Open Peer Reviewers whose suggestions have been incorporated into the manuscript. Rosalind Raine was (in part) supported by theNational Institute for Health Research (NIHR) Collaboration for Leadership inApplied Health Research and Care (CLAHRC) North Thames at Bart's Health NHSTrust. The views expressed are those of the author(s) and not necessarily thoseof the NHS, the NIHR or the Department of Health and Social Care.

Contributors MN and MM conceived the study. RR and RA had critical input into study direction and interpretation. MN and GK extracted and sorted data for the study. MN performed the analysis and wrote the first draft of the manuscript. All authors contributed to critical revision of the manuscript for important intellectual content and approved the final version. MN and MM are the guarantors.

Funding The authors have not declared a specific grant for this research from any funding agency in the public, commercial or not-for-profit sectors.

Competing interests MM serves as NHS England's Innovation Adviser and is a cofounder of Cera, a technology-enabled homecare provider.

Patient consent for publication Not required.

Provenance and peer review Not commissioned; externally peer reviewed.

Data sharing statement Raw data and analysis available on request from authors.

Open access This is an open access article distributed in accordance with the Creative Commons Attribution Non Commercial (CC BY-NC 4.0) license, which permits others to distribute, remix, adapt, build upon this work non-commercially, and license their derivative works on different terms, provided the original work is properly cited, appropriate credit is given, any changes made indicated, and the use is non-commercial. See: http://creativecommons.org/licenses/by-nc/4.0/.

\section{REFERENCES}

1. Lorenzoni L, Belloni A, Sassi F. Health-care expenditure and health policy in the USA versus other high-spending OECD countries. Lancet 2014;384:83-92.

2. NHS. Five year forward view. 2014 http://www.england.nhs.uk/wpcontent/uploads/2014/10/5yfv-web.pdf (Accessed 29 Aug 2017).

3. Gulland A. NHS chief warns of more financial challenges. BMJ 2017;356:j212.

4. NHS Improvement. 10 ways for NHS providers to find savings and make cost improvementsAvailable online at. $2016 \mathrm{https} / / /$ improvement.nhs.uk/uploads/documents/FIP_-_where_to_look_to_ make_NHS_savings.pdf (Accessed 29 Aug 2017).

5. Campbell D, Morris S, Marsh S. NHS faces 'humanitarian crisis' as demand rises, British Red Cross warns. 2017 https://www. theguardian.com/society/2017/jan/06/nhs-faces-humanitarian-crisisrising-demand-british-red-cross (Accessed 29 Aug 2017).

6. NHS Improvement. Quarterly performance of the NHS provider sector: quarter 3 2016/17. 2017 https://improvement.nhs.uk/ resources/quarterly-performance-nhs-provider-sector-quarter-31617/ (Accessed 29 Aug 2017).

7. NHS England. NHS England business plan. $2016 \mathrm{https} / / / \mathrm{www}$. england.nhs.uk/wp-content/uploads/2016/03/bus-plan-16.pdf (Accessed 29 Aug 2017).

8. Hopson C. We need to be honest and realistic about what is deliverable at the NHS front line. 2017 http://blogs.bmj.com/bmj/ 2017/01/29/chris-hopson-we-need-to-be-honest-and-realisticabout-what-is-deliverable-at-the-nhs-front-line/ (Accessed 29 August 2017).

9. QualityWatch. Indicators. http://www.qualitywatch.org.uk/indicatorsresults (Accessed 7 May 2018).

10. Gov.uk. NHS trusts accounts data for 2015 to 2016. $2016 \mathrm{https} / / /$ www.gov.uk/government/publications/nhs-trusts-accounts-data-for2015-to-2016 (Accessed 29 Aug 2017).

11. Gov.uk. The Quarter, quarter 4 2010/11. 2011 https://www.gov.uk/ government/publications/the-quarter-quarter-4-2010-11 (Accessed 29 Aug 2017).

12. NHS England. Bed availability and occupancy. $2017 \mathrm{https} / / \mathrm{www}$. england.nhs.uk/statistics/statistical-work-areas/bed-availability-andoccupancy/ (Accessed 29 Aug 2017).

13. Association of UK University Hospital Trusts. List of AUKUH members. 2016 http://www.aukuh.org.uk/index.php/members/ aukuh-members (Accessed 29 August 2017).

14. Gov.uk. English indices of deprivation 2015. $2015 \mathrm{https} / / / \mathrm{www}$. gov.uk/government/statistics/english-indices-of-deprivation-2015 (Accessed 29 Aug 2017).

15. England NHS. Statistical work areas. $2017 \mathrm{https} / / / \mathrm{www}$.england.nhs. uk/statistics/statistical-work-areas/ (Accessed 29 Aug 2017).

16. Surveys NHS. Current surveys. 2017 http://www.nhssurveys.org/ surveys (Accessed 29 Aug 2017).

17. Bazzoli GJ, Chen HF, Zhao M, et al. Hospital financial condition and the quality of patient care. Health Econ 2008;17:977-95.

18. Encinosa WE, Bernard DM. Hospital finances and patient safety outcomes. Inquiry 2005;42:60-72.

19. Joynt KE, Orav EJ, Jha AK. Association between hospital conversions to for-profit status and clinical and economic outcomes. JAMA 2014;312:1644-52.

20. Volpp KG, Konetzka RT, Zhu J, et al. Effect of cuts in Medicare reimbursement on process and outcome of care for acute myocardial infarction patients. Circulation 2005;112:2268-75.

21. Ly DP, Jha AK, Epstein AM. The association between hospital margins, quality of care, and closure or other change in operating status. J Gen Intern Med 2011;26:1291-6.

22. Aiken LH, Sloane DM, Bruyneel L, et al. Nurse staffing and education and hospital mortality in nine European countries: a retrospective observational study. Lancet 2014;383:1824-30.

23. Gainsbury S. The bottom line. Understanding the NHS deficit and why it won't go away: The Nuffield Trust. $2017 \mathrm{https} / / \mathrm{www}$. nuffieldtrust.org.uk/research/the-bottom-line-understanding-the-nhsdeficit-and-why-it-won-t-go-away (Accessed 4 Oct 2018).

24. The Health Foundation. System-wide problems driving NHS deficit. 2016 http://www.health.org.uk/news/system-wide-problems-drivingnhs-deficit (Accessed 29 Aug 2017). 